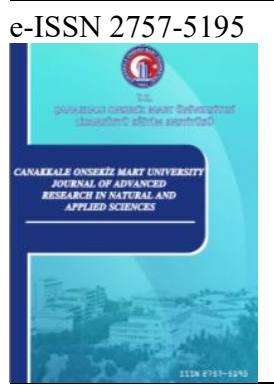

Çanakkale Onsekiz Mart University

Journal of Advanced Research in Natural and Applied Sciences

Open Access

\title{
Yedi Akdeniz Lamiaceae Türünün Duman ve Duman Kökenli Bileşiklere Olan Çimlenme Tepkisi
}

\author{
Şükrü Serter Çatavi,,", Kenan Akbaş² \\ ${ }^{1}$ Biyoloji Bölümü, Fen Fakültesi, Muğla Sttkı Koçman Üniversitesi, Muğla, Türkiye \\ ${ }^{2}$ Bitkisel ve Hayvansal Üretim Bölümü, Köyceğiz Meslek Yüksekokulu, Muğla Sitkı Koçman Üniversitesi, Muğla, Türkiye
}

\begin{abstract}
Makale Tarihçesi
Gönderim: $\quad 11.05 .2021$

Kabul: $\quad 16.08 .2021$

Yayım: $\quad 15.12 .2021$
\end{abstract}

Araștırma Makalesi

\begin{abstract}
Öz - Bitki kökenli dumanın, Akdeniz tipi ekosistemlerde yetişen birçok Lamiaceae türünün çimlenmesini tetiklediği gösterilmiştir. Bununla birlikte, Lamiaceae türlerinin karrikinolid $\left(\mathrm{KAR}_{1}\right)$ ve siyanohidrin gibi duman kökenli bileşiklere olan çimlenme tepkileri hakkında çok az şey bilinmektedir. Bu nedenle, bu çalışmada, duman bileşiklerin yedi Akdeniz Lamiaceae türünde (Ballota acetabulosa, Lavandula stoechas subsp. stoechas, Origanum onites, Phlomis bourgaei, P. lycia, Stachys cretica subsp. smyrnaea ve Teucrium chamaedrys) tohum çimlenmesi üzerindeki etkilerini belirlemeyi amaçladık. Bu hedefe ulaşmak için çalışma türlerinin tohumları farklı konsantrasyonlarda duman-suyu, $\mathrm{KAR}_{1}$, mandelonitril (MAN) ve $\mathrm{KAR}_{1}+\mathrm{MAN}$ 'a maruz bırakılmıştır. Uygulama gruplarına ait tohumlar daha sonra karanlık koşullarda $20^{\circ} \mathrm{C}$ 'de inkübe edilmiş ve 35 gün boyunca haftada iki kez çimlenme sayımları yapılmıştır. Sonuçlarımız, dumanın kontrol koșullarına göre $B$. acetabulosa, $P$. lycia ve $S$. cretica'nın çimlenme yüzdelerinde önemli bir artışa yol açtı̆̆ını göstermektedir. $\mathrm{KAR}_{1}, B$. acetabulosa ve $S$. cretica'nın çimlenmesini uyarırken, MAN uygulamaları Lamiaceae türlerinin çimlenmesini teşvik etmemiştir. $\mathrm{KAR}_{1}$ ve MAN kombinasyonu dumana duyarlı üç türün çimlenmesini tetiklemekle kalmamış, aynı zamanda $T$. chamaedrys'in çimlenme yüzdesini de önemli ölçüde arttırmıştır. Sonuç olarak, çalışmamız, dumanın Lamiaceae türlerinin çimlenmesi üzerinde olumlu bir etkiye sahip olduğu fikrini desteklemekte ve $\mathrm{KAR}_{1}$ ve siyanohidrinin birlikte uygulanmasının, tohum çimlenmesinin uyarılmasında, bu iki bileşiğin ayrı ayrı uygulanmasına göre daha etkili olduğuna dair kanıtlar sağlamaktadır.
\end{abstract}

Anahtar Kelimeler - Bitki kökenli duman, karrikinolid, Lamiaceae, siyanohidrin, tohum çimlenmesi

\section{Germination Response of Seven Mediterranean Lamiaceae Species to Smoke and Smoke-derived Compounds}

${ }^{1}$ Department of Biology, Faculty of Science, Muğla Sitkı Koçman University, Muğla, Turkey

${ }^{2}$ Department of Herbal and Animal Production, Köyceğiz Vocational School, Muğla Sitkı Koçman University, Muğla, Turkey

Article History

Received: $\quad 11.05 .2021$

Accepted: $\quad 16.08 .2021$

Published: $\quad 15.12 .2021$

Research Article
Abstract - Plant-derived smoke has been shown to trigger germination of many Lamiaceae species growing in Mediterranean-type ecosystems. However, very little is known about the germination response of Lamiaceae species to smoke-derived compounds, such as karrikinolide $\left(\mathrm{KAR}_{1}\right)$ and cyanohydrin. In this work, therefore, we aimed to ascertain the effects of smoke-derived compounds on seed germination in seven Mediterranean Lamiaceae species (Ballota acetabulosa, Lavandula stoechas subsp. stoechas, Origanum onites, Phlomis bourgaei, P. lycia, Stachys cretica subsp. smyrnaea, and Teucrium chamaedrys). To achieve this goal, seeds of study species were exposed to different concentrations of smoke-water, $\mathrm{KAR}_{1}$, mandelonitrile (MAN), and $\mathrm{KAR}_{1}+\mathrm{MAN}$. Seeds from treatment groups were then incubated at $20^{\circ} \mathrm{C}$ in dark conditions, and germination counts were made twice weekly for 35 days. Our results show that smoke leads to a significant increase in germination percentage of B. acetabulosa, $P$. lycia, and $S$. cretica as compared to control conditions. $\mathrm{KAR}_{1}$ stimulated the germination of $B$. acetabulosa and $S$. cretica while MAN treatments did not promote the germination of Lamiaceae species. The combination of $\mathrm{KAR}_{1}$ and MAN not only induced the germination of three smoke-sensitive species but also notably increased the germination percentage of $T$. chamaedrys. In conclusion, our study supports the idea that smoke has a positive impact on the germination of Lamiaceae species and provides evidence that combined application of $\mathrm{KAR}_{1}$ and cyanohydrin is more effective in the stimulation of seed germination than the separate application of these two compounds. 


\section{Giriş}

Dünyadaki karasal alanların \%30'dan fazlası sıklıkla yangınlara maruz kalmaktadır (Chuvieco, Giglio, ve Justice, 2008). Doğal yangın rejimleri, bu bölgelerdeki biyolojik çeşitliliğin ve ekolojik süreçlerin korunmasına katkı sağlamaktadır (He, Lamont, ve Puasas, 2019). Birçok bitki türü, yangın sonrasındaki mevcudiyetlerini devam ettirebilmek için çeşitli uyumsal özellikler geliştirmiştir. Sürgün verme, yangınla indüklenen tohum çimlenmesi, farklı yanıcılık stratejileri, serotinlik (tohum bekletme), kalın kabuk gelişimi ve yangınla uyarılan çiçeklenme bu uyumsal özelliklerin başta gelen örnekleridir (Keeley, Pausas, Rundel, Bond, ve Bradstock, 2011).

Yangın ile indüklenen tohum çimlenmesi, sıcaklık ve/veya yanma ile ilişkili ürünlerin (duman, karrikinler, azotlu bileşikler vb.) dormansi kırıcı etkilerinden kaynaklanmaktadır (Çatav, Küçükakyüz, Tavşanoğlu, ve Pausas, 2018). Bir orman yangını sırasında toprak yüzey sıcaklı $\breve{g}_{1} 800^{\circ} \mathrm{C}$ 'ye kadar ulaşabilirken, toprak tohum bankası (toprak yüzeyinin 3-5 cm altı) 80 ila $150{ }^{\circ} \mathrm{C}^{\prime}$ lik bir sıcaklığa maruz kalmaktadır (Newton, Bond, ve Farrant, 2006). Toprak tohum bankasına yansıyan bu sıcaklıklar, çoğunlukla fiziksel dormansiye sahip Cistaceae, Fabaceae ve Malvaceae türlerinde tohum çimlenmesini uyarmaktadır (Kazancı ve Tavşanoğlu, 2019). Duman ve nitratın tohum çimlenmesi üzerindeki pozitif etkileri de, farklı ekolojik ve filogenetik kökenlere ait birçok bitki türünde gösterilmiştir (Arcamone ve Jaureguiberry, 2018; Çatav, Küçükakyüz, Tavşanoğlu, ve Akbaş, 2015; Flematti vd., 2011).

Dumanın çimlenme üzerindeki etki mekanizmasını belirlemeye yönelik çalışmalar, birçok duman kökenli bileşiğin izole edilmesine neden olmuştur. Bitki kökenli dumandan izole edilen ilk aktif bileşik (3-metil-2Hfuro[2,3-c]piran-2-on), dumana duyarlı 16 türün tamamında çimlenmeyi uyarmıştır (Flematti, Ghisalberti, Dixon, ve Trengove, 2004). Bu bileşik daha sonra karrikinolid $\left(\mathrm{KAR}_{1}\right)$ olarak adlandırılmış ve etkinliği dumana yanıt veren birçok bitki türü üzerinde incelenmiştir. İlerleyen y1llarda $5 \mathrm{KAR}_{1}\left(\mathrm{KAR}_{2}-\mathrm{KAR}_{6}\right)$ analoğu daha tespit edilmiş ve bu bileşikler topluca karrikinler adıyla anılmaya başlanmıştır (Nelson, Flematti, Ghisalberti, Dixon, ve Smith, 2012). Anigozanthos manglesii ve Rhodocoma arida gibi dumana duyarl1 olan baz1 türlerin $\mathrm{KAR}_{1}$ 'e yanıt vermemeleri, gliseronitril (2,3-hidroksipropannitril) olarak da bilinen bir siyanohidrinin tanımlanmasına yol açmıştır. Dumandan izole edilen bu yeni bileşiğin, su varlığında hidrolize olduğu ve açığa çıkan serbest siyanürün de tohum çimlenmesini teşvik ettiği belirlenmiştir (Flematti vd., 2011). Öte yandan, dumanda bulunan bazı bileşiklerin çimlenmeyi inhibe edebilecekleri de bilinmektedir (Küçükakyüz ve Çatav, 2021). Örneğin, 3,4,5-trimetilfuran-2(5H)-on (TMB) ve 5,5-dimetilfuran-2(5H)-on'un $10 \mu \mathrm{M}$ ve üzeri konsantrasyonlarda $\mathrm{KAR}_{1}$ karşı antagonistik bir etki gösterdikleri saptanmıştır (Burger vd., 2018).

Lamiaceae (Ballıbabagiller) familyası dünya genelinde yaklaşık olarak 230 cins ve 7000 tür ile temsil edilmektedir. Familya kozmopolit bir dağılım göstermekle birlikte, özellikle Akdeniz, İran-Turan ve Doğu Asya bölgelerinde büyük bir çeşitlilik sergilemektedir (Çatav, Küçükakyüz, Akbaş, ve Tavşanoğlu, 2014). Türkiye florasında 256 tanesi endemik olmak üzere toplam 574 Lamiaceae türü bulunmaktadır (Erik ve Tarıkahya, 2004). Familyanın birçok üyesi tıbbi ve ekonomik öneme sahip olup, biberiye (Rosmarinus officinalis L.), fesleğen (Ocimum basilicum L.), kekik (Thymus vulgaris L.) ve nane (Mentha x piperita L.) gibi türler baharat olarak kullanılmaktadır (Simpson, 2010; Quílez, Ferreres, López-Miranda, Salazar, ve Jordán, 2020).

Bitki kökenli dumanın Akdeniz tipi ekosistemlerde yetişen birçok Lamiaceae türünde çimlenmeyi uyardı̆̆ 1 gösterilmiştir (Çatav vd., 2014; Moreira, Tormo, Estrelles, ve Pausas, 2010). Bununla birlikte, Lamiaceae türlerinin duman kökenli bileşiklere verdikleri çimlenme yanıtı hakkında oldukça az bilgi bulunmaktadır (Çatav vd., 2018). Bu eksikliği gidermek için mevcut çalışmada duman suyu, mandelonitril (bir siyanohidrin analoğu) ve $\mathrm{KAR}_{1}$ 'in 7 Lamiaceae türünün çimlenmeleri üzerindeki etkileri incelenmiştir. Bu araştırma kapsamında, (1) dumana cevap veren türlerin $\mathrm{KAR}_{1}$ ve siyanohidrin bileşiklerinden birine daha duyarlı olacağı ve (2) bu iki bileşiğin kombine uygulamasının çimlenme üzerinde sinerjistik bir etki yaratabileceği hipotez edilmiştir. 


\section{Materyal ve Yöntem}

\section{1. Çalışma Bölgesi ve Tohumların Toplanması}

$\mathrm{Bu}$ çalışmada, kızılçam ormanı açıklıklarında ve makilik alanlarda doğal olarak yetişen 7 Lamiaceae türüne ait meyveler toplanmıştır. Seçilen türlerin taksonomik ve ekolojik özellikleri Tablo 1'de belirtilmiştir. Çalışma bölgesi (Muğla - Marmaris), yıllık 1208,3 mm yağış ve 15,1 ${ }^{\circ} \mathrm{C}$ ortalama sıcaklık ile tipik bir Akdeniz iklimine sahiptir (Meteoroloji Genel Müdürlüğü verileri). Arazi çalışmaları, incelenen türlerin tohum dispersal periyodlarına denk gelecek şekilde, Temmuz ve Ağustos 2016 tarihleri arasında gerçekleştirilmiştir. Tohumlar ayıklandıktan sonra, deney başlangıcına kadar (Aralık 2016) oda koşullarında muhafaza edilmiştir. Her bir türe ait ortalama tohum ağırlı̆̆ (mg), 100 tohumun 4 farklı örneğinin tartılması ile hesaplanmıştır.

Tablo 1

Çalışma türlerinin listesi. BF: Büyüme formu (ÇO: çok yıllık ot, Ç: çalı ve YÇ: yarı çalı), SY: Sürgün verme yeteneği ("+" = evet, "“-" = hayır) ve TA: ortalama tohum ağırlı̆̆ $(\mathrm{mg})$.

\begin{tabular}{lcccc}
\hline Türler & Kod & BF & SY & TA \\
\hline Ballota acetabulosa (L.) Benth. (Hoş nemnem) & BAC & ÇO & + & $1.81 \pm 0.09$ \\
Lavandula stoechas L. subsp. stoechas L. (Karabaş otu) & LST & Ç & - & $0.60 \pm 0.02$ \\
Origanum onites L. (Bilyalı kekik - İzmir kekiği) & OON & YÇ & + & $0.06 \pm 0.00$ \\
Phlomis bourgaei Boiss. (Çoban çırasi) & PBO & Ç & + & $5.49 \pm 0.25$ \\
Phlomis lycia D. Don (Tüylü çalba) & PLY & Ç & + & $5.57 \pm 0.10$ \\
Stachys cretica L. subsp. smyrnaea Rech. Fil. (İzmir deliçay1) & SCR & ÇO & - & $2.83 \pm 0.04$ \\
Teucrium chamaedrys L. subsp. chamaedrys L. (Kisamahmut) & TCH & ÇO & + & $0.89 \pm 0.03$ \\
\hline
\end{tabular}

\subsection{Duman Suyu ve Kimyasal Çözeltilerin Hazırlanması}

Duman suyunu hazırlamak için 80 gram buğday samanı bir arı körüğünde yakılmış ve oluşan duman 12 dakika boyunca $500 \mathrm{~mL}$ distile suya gönderilmiştir (Çatav vd., 2018). Elde edilen çözelti (100\% konsantrasyon), bir Whatman filtre kağıdı (no. 42) kullanılarak süzülmüş ve deney başlangıcına kadar $4{ }^{\circ} \mathrm{C}$ 'de saklanmıştır. $\mathrm{KAR}_{1}$ (Carbosynth, CAS numarası: 857054-02-5) ve mandelonitril (Sigma, CAS numarası: 532-28-5) stok çözeltileri ise ilgili bileşiklerin sırasıyla etanol ve distile su içinde çözülmeleriyle hazırlanmıştır (Küçükakyüz ve Çatav, 2021).

\section{3. Çimlenme Deneyi}

Duman ve duman kökenli bileşiklerin Lamiaceae türlerinin çimlenmeleri üzerindeki etkilerini değerlendirmek için 8 uygulama gerçekleştirilmiştir (Tablo 2). Ayrıca her bir tür için deneye bir kontrol grubu da dâhil edilmiştir. Uygulamalar için seçilen nihai konsantrasyonlar daha önceki araştırmalara göre belirlenmiştir (Flematti vd., 2011; Downes, Light, Pošta, Kohout, ve van Staden, 2013; Tavşanoğlu vd., 2017).

Deney kapsamında, Lamiaceae türlerinin tohumları, $10 \mathrm{~mL}$ distile su (kontrol) veya uygulama solüsyonları ile nemlendirilmiş iki adet Whatman filtre kâğıdı (no. 1) içeren Petri kaplarına yerleştirilmiştir. Petri kapları daha sonra $20.0 \pm 0.5^{\circ} \mathrm{C}^{\prime}$ ye ayarlanmış bir inkübatöre aktarılarak, 5 hafta boyunca karanlık koşullarda bekletilmiştir (Çatav vd., 2014). Çimlenme kontrolleri, haftada iki kez loş 1şı altında yapılmış ve görünür radikula (kökçük) çıkışı çimlenme kriteri olarak kabul edilmiştir. Çimlenmeyen tohumların canlılıkları kesme testi ile incelenmiş ve embriyosu olmayan tohumlar veri setinden çıkarılmıştır. 
Tablo 2

Çalışmada gerçekleştirilen uygulamalar

\begin{tabular}{ccccc}
\hline \multicolumn{2}{c}{ Uygulama } & \multicolumn{3}{c}{ Final konsantrasyonu } \\
\hline No & Kod & Duman suyu $(\%)$ & Karrikinolid $(\mu \mathrm{M})$ & Mandelonitril $(\mu \mathrm{M})$ \\
\hline 1 & DS & 2.5 & - & - \\
2 & DS & 5 & - & - \\
3 & KAR $_{1}$ & - & 0.01 & - \\
4 & KAR $_{1}$ & - & 0.1 & - \\
5 & MAN & - & - & 5 \\
6 & MAN & - & - & 50 \\
7 & K-1 & - & 0.01 & 5 \\
8 & K-2 & - & 0.1 & 50 \\
\hline
\end{tabular}

\subsection{Veri Analizi}

Bu deneyde, her bir uygulama için 25 tohumun 3 tekrarı kullanılmıştır. Uygulamalar tarafından çimlenmenin uyarılma olasıllı̆ı, binom dağılımı baz alan genelleştirilmiş bir doğrusal model (GLM) ile test edilmiştir (Çatav vd., 2015). Çok sayıda ikili karşılaştırma bulunması nedeniyle, istatistiksel anlamlılık düzeyi $p<0.01$ olarak seçilmiştir. Veri analizi için R (sürüm 3.4.3) ve Statistica (sürüm 10) yazılımları kullanılmıştır.

\section{Bulgular ve Tartışma}

Bu çalışma kapsamında, duman, $\mathrm{KAR}_{1}$ ve MAN'ın 7 Lamiaceae türünün çimlenmeleri üzerindeki etkileri test edilmiştir. Kontrol koşullarında, 4 türde (Phlomis bourgaei, P. lycia, Stachys cretica ve Teucrium chamaedrys) tohumların $\% 2$ ila $\% 25$ 'i çimlenirken, 3 türde (Ballota acetabulosa, Lavandula stoechas ve Origanum onites) tohumların \%60 ila \%83'ü çimlenmiştir. Bu da, çalışma türlerinde dormansi seviyesi açısından önemli bir değişkenliğin olduğunu göstermektedir (varyasyon katsayıs1 $=0.809$ ). Duman suyu uygulamaları, kontrol gruplarına göre $B$. acetabulosa, $P$. lycia ve $S$. cretica türlerinde çimlenme yüzdesini anlamlı olarak ( $p$ $<0.01$ ) arttırmıştır (Tablo 3). Elde edilen bu sonuçlar, Moreira vd. (2010) ve Çatav vd. (2014)'ün bulguları ile uyumlu olup, dumanın Akdeniz Lamiaceae türlerinin çimlenmeleri üzerindeki pozitif etkisini doğrulamaktadir.

Tablo 3

Duman ve duman kökenli bileşiklerin Lamiaceae türlerinin çimlenmeleri (\%) üzerine etkileri

\begin{tabular}{|c|c|c|c|c|c|c|c|c|c|}
\hline \multirow[t]{2}{*}{ Türler } & \multirow[t]{2}{*}{ Kontrol } & \multicolumn{2}{|c|}{ DS (\%) } & \multicolumn{2}{|c|}{$\mathrm{KAR}_{1}(\boldsymbol{\mu M})$} & \multicolumn{2}{|c|}{ MAN $(\mu M)$} & \multicolumn{2}{|c|}{$\mathrm{KAR}_{1}+\mathrm{MAN}$} \\
\hline & & 2.5 & 5 & 0.01 & 0.1 & 5 & 50 & $\mathrm{~K}-1$ & $\mathrm{~K}-2$ \\
\hline BAC & $60 \pm 10^{\mathrm{b}}$ & $89 \pm 6^{a}$ & $91 \pm 2^{\mathrm{a}}$ & $75 \pm 7^{\mathrm{ab}}$ & $88 \pm 6^{a}$ & $75 \pm 6^{\mathrm{ab}}$ & $80 \pm 4^{\mathrm{ab}}$ & $94 \pm 0^{a}$ & $84 \pm 8^{a b}$ \\
\hline LST & $82 \pm 0^{\mathrm{a}}$ & $96 \pm 2^{a}$ & $96 \pm 3^{a}$ & $95 \pm 3^{a}$ & $96 \pm 3^{a}$ & $97 \pm 3^{\mathrm{a}}$ & $98 \pm 2^{\mathrm{a}}$ & $97 \pm 2^{\mathrm{a}}$ & $98 \pm 2^{\mathrm{a}}$ \\
\hline OON & $83 \pm 6^{\mathrm{a}}$ & $91 \pm 2^{\mathrm{a}}$ & $90 \pm 3^{\mathrm{a}}$ & $92 \pm 2^{\mathrm{a}}$ & $92 \pm 2^{\mathrm{a}}$ & $97 \pm 2^{\mathrm{a}}$ & $89 \pm 3^{\mathrm{a}}$ & $95 \pm 0^{\mathrm{a}}$ & $89 \pm 3^{a}$ \\
\hline PBO & $17 \pm 9^{\mathrm{a}}$ & $14 \pm 10^{\mathrm{a}}$ & $11 \pm 5^{\mathrm{a}}$ & $19 \pm 5^{\mathrm{a}}$ & $18 \pm 10^{\mathrm{a}}$ & $15 \pm 3^{\mathrm{a}}$ & $11 \pm 7^{\mathrm{a}}$ & $27 \pm 11^{\mathrm{a}}$ & $24 \pm 2^{\mathrm{a}}$ \\
\hline PLY & $25 \pm 2^{\mathrm{b}}$ & $47 \pm 5^{a}$ & $45 \pm 3^{a b}$ & $34 \pm 7^{\mathrm{ab}}$ & $45 \pm 4^{\mathrm{ab}}$ & $28 \pm 4^{\mathrm{ab}}$ & $36 \pm 10^{\mathrm{ab}}$ & $46 \pm 2^{\mathrm{ab}}$ & $50 \pm 9^{a}$ \\
\hline SCR & $2 \pm 2^{b}$ & $41 \pm 9^{a}$ & $54 \pm 8^{a}$ & $46 \pm 11^{\mathrm{a}}$ & $65 \pm 7^{a}$ & $3 \pm 2^{b}$ & $10 \pm 3^{b}$ & $62 \pm 10^{a}$ & $64 \pm 2^{a}$ \\
\hline $\mathrm{TCH}$ & $19 \pm 6^{\mathrm{b}}$ & $34 \pm 9^{\mathrm{ab}}$ & $22 \pm 2^{\mathrm{ab}}$ & $29 \pm 8^{\mathrm{ab}}$ & $31 \pm 3^{\mathrm{ab}}$ & $28 \pm 11^{\mathrm{ab}}$ & $21 \pm 3^{\mathrm{ab}}$ & $41 \pm 8^{a}$ & $40 \pm 7^{\mathrm{ab}}$ \\
\hline
\end{tabular}

Sonuçlar, ortalama \pm standart hata şeklinde sunulmuştur. Tür ve uygulama kodları için sırasıyla Tablo 1 ve Tablo 2'ye bakınız. Aynı satırda farklı üst simge harfleri olan değerler birbirinden önemli ölçüde farklıdır $(p<0.01)$. Kontrolden anlamlı olarak farklı olan değerler ayrıca koyu renk ile gösterilmiştir.

Şu ana kadar, bu çalışmanın da dâhil olduğu 9 araştırmada, duman, $\mathrm{KAR}_{1}$ ve siyanohidrin türevlerinin tohum çimlenmesi üzerindeki etkileri karşılaştırmalı olarak incelenmiştir (Tablo 4). Bu araştırmalarda 17 bitki familyasına ait 40 türün tohumları kullanılmıştır. Elde edilen sonuçlar, dumanla uyarılan çimlenmenin oldukça 
kompleks bir süreç olduğunu düşündürmektedir. Örneğin, Haemodoraceae familyasında yer alan Anigozanthos türlerinin siyanohidrine cevap verirken, $\mathrm{KAR}_{1}$ 'e cevap vermedikleri belirlenmiştir (Flematti vd., 2011; Downes, Light, Pošta, Kohout, ve van Staden, 2014; Ma, Erickson, Walck, ve Merritt, 2020). Öte yandan, aynı familyada yer alan çoğu Conostylis türünün her iki bileşiğe de duyarlı oldukları tespit edilmiştir (Downes, Light, Pošta, ve van Staden, 2015). Mevcut çalışmanın bulguları, MAN uygulamalarının Lamiaceae türlerinde çimlenmeyi doğrudan uyarmadığını göstermektedir (Tablo 3 ). $\mathrm{KAR}_{1}$ uygulamaları ise dumana duyarlı türlerin ikisinde (B. acetabulosa ve S. cretica) çimlenmeyi tetiklemiş̧ir.

Çatav vd. (2018) tarafından gerçekleştirilen bir çalışmada, dumana pozitif çimlenme yanıtı veren Alyssum fulvescens' in $\mathrm{KAR}_{1}$ ve MAN'a karşı duyarlı olmadığı saptanmıştır. Bununla birlikte, MAN ve KAR ${ }_{1}$ in kombine uygulaması, aynı türde çimlenmeyi kontrol koşullarına göre önemli ölçüde arttırmıştır. Dahası, bu iki bileşiğin birlikte uygulanmasının Capsella bursa-pastoris, Chaenorhinum rubrifolium ve Silene behen gibi türlerin çimlenmeleri üzerinde sinerjistik veya aditif (katma) etkiler yaratabileceği de gösterilmiş̧ir (Tavşanoğlu vd., 2017; Çatav vd., 2018). Sonuçlarımız, P. lycia türünün duman ve K-2 $(0.1 \mu \mathrm{M} \mathrm{KAR}+50 \mu \mathrm{M}$ MAN) uygulamalarına yanıt verirken, $\mathrm{KAR}_{1}$ ve MAN uygulamalarına yanıt vermediğini ortaya koymuştur (Tablo 3). Buna ek olarak, K-1 (0.01 $\left.\mu \mathrm{M} \mathrm{KAR}_{1}+5 \mu \mathrm{M} \mathrm{MAN}\right)$ uygulamasının $S$. cretica'nın çimlenmesi üzerinde sinerjistik bir etkiye sahip olduğu tespit edilmiştir. Son olarak, çalışma türlerinde kontrol gruplarına göre çimlenme yüzdesini en çok arttıran uygulama K-1 olarak bulunmuştur (Şekil 1).

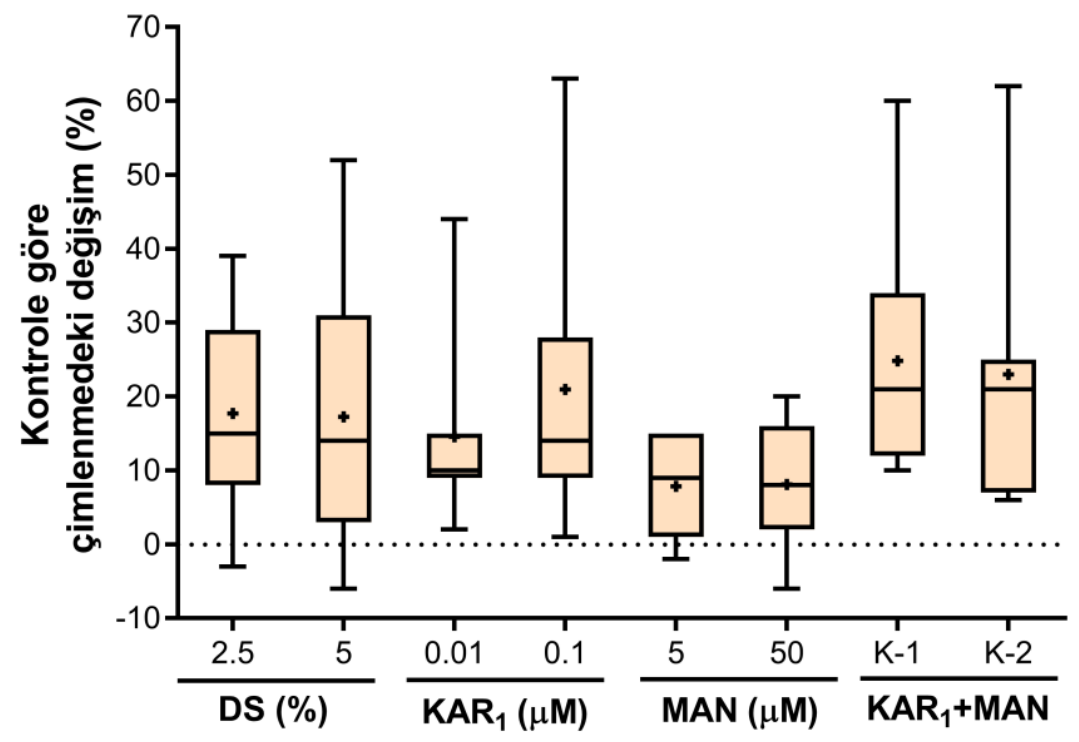

Şekil 1. Duman ve duman kökenli bileşiklerin çalışma türlerinin çimlenmeleri üzerindeki genel etkileri. Kutu grafikleri, ilgili uygulama sonrasında kontrol gruplarına göre çimlenme yüzdesinde meydana gelen farkların kullanılması ile oluşturulmuştur. Kutulardaki çizgi ve artı işareti sırasıyla medyan ve ortalamayı temsil etmektedir.

Tablo 4'deki veriler göz önüne alındığında, dumana cevap vermeyen bazı türlerin (Anigozanthos rufus, Emmenanthe penduliflora ve Sanguisorba minor) duman kökenli bileşiklere karşı duyarlı olabildikleri görülmektedir (Flematti vd., 2011; Downes vd., 2014; Çatav vd., 2018). Mevcut çalışmada, Teucrium chamaedrys türü için de benzer bir bulgu elde edilmiştir (Tablo 3). T. chamaedrys'de tohum çimlenmesi KAR ${ }_{1}$ ve MAN kombine uygulaması tarafından uyarılırken, duman uygulaması tarafından uyarılmamıştır. Bu tutarsızlığa, yöntemsel farklılıklar ve uygulanan duman suyu konsantrasyonu neden olabilir. Örneğin, Gupta vd. (2020), farklı yıllarda ve farklı yöntemler ile hazırlanan duman sularındaki $\mathrm{KAR}_{1}, \mathrm{KAR}_{2}$ ve TMB içeriklerinin oldukça farklı olabileceğini göstermiştir. Ayrıca, TMB'nin de dâhil olduğu bir grup duman kökenli bileşiğin yüksek seviyelerde tohum çimlenmesini inhibe edebildikleri de bilinmektedir (Burger vd., 2018). Bu kapsamda, bir bitkinin tohumları aynı konsantrasyondaki iki farklı duman suyuna benzer bir tepki vermeyebilir (Çatav vd., 2018). 
Bunlara ek olarak, bir türün dumana olan duyarlılığında popülasyonlar arası varyasyonun olabileceği de rapor edilmiştir (Ma vd., 2020).

Tablo 4

Duman, $\mathrm{KAR}_{1}$ ve siyanohidrin türevlerinin tohum çimlenmesi üzerindeki etkilerinin karşılaştırmalı olarak incelendiği bitki türleri. D: Duman suyu, K: $\mathrm{KAR}_{1}$ ve S: Siyanohidrin. "+": İlgili uygulama çimlenmeyi uyarmıştır. “-”: İlgili uygulama çimlenmeyi uyarmamıştır. T.E: Uygulama test edilmemiştir.

\begin{tabular}{|c|c|c|c|c|c|c|}
\hline Familya & Tür & D & $\mathbf{K}$ & $\mathbf{S}$ & $\mathbf{K}+\mathbf{S}$ & Referans \\
\hline Asteraceae & Onopordum caricum & + & + & - & + & Çatav vd. (2018) \\
\hline Boraginaceae & Emmenanthe penduliflora & - & + & + & T.E & Flematti vd. (2011) \\
\hline \multirow{3}{*}{ Brassicaceae } & Alyssum fulvescens & + & - & - & + & Çatav vd. (2018) \\
\hline & Capsella bursa-pastoris & - & - & - & + & Çatav vd. (2018) \\
\hline & Isatis tinctoria & + & - & - & - & Çatav vd. (2018) \\
\hline Caryophyllaceae & Silene behen & - & - & + & + & Çatav vd. (2018) \\
\hline Cistaceae & Helianthemum salicifolium & + & - & - & - & Çatav vd. (2018) \\
\hline Cyperaceae & Ficinia nodosa & + & + & + & T.E & Flematti vd. (2011) \\
\hline Ericaceae & Andersonia latiflora & + & + & + & T.E & Flematti vd. (2011) \\
\hline \multirow{20}{*}{ Haemodoraceae } & Anigozanthos bicolor & + & - & + & T.E & Downes vd. (2014) \\
\hline & A. flavidus & + & - & + & T.E & Ma vd. (2020) \\
\hline & A. flavidus & + & - & + & T.E & Downes vd. (2014) \\
\hline & A. gabrielae & + & - & + & T.E & Downes vd. (2014) \\
\hline & A. humilis & - & - & + & T.E & Flematti vd. (2011) \\
\hline & A. humilis & + & - & + & T.E & Downes vd. (2014) \\
\hline & A. manglesii & + & - & + & T.E & Flematti vd. (2011) \\
\hline & A. manglesii & + & - & + & T.E & Downes vd. (2014) \\
\hline & A. rufus & - & - & + & T.E & Downes vd. (2014) \\
\hline & A. viridis & + & - & + & T.E & Flematti vd. (2011) \\
\hline & A. viridis & + & - & + & T.E & Downes vd. (2014) \\
\hline & Blancoa canescens & + & + & - & T.E & Downes vd. (2014) \\
\hline & Conostylis aculeata & + & + & + & T.E & Downes vd. (2015) \\
\hline & C. angustifolia & + & + & - & T.E & Downes vd. (2015) \\
\hline & C. candicans & + & + & + & T.E & Flematti vd. (2011) \\
\hline & C. canteriata & + & + & + & T.E & Downes vd. (2015) \\
\hline & C. juncea & + & + & + & T.E & Downes vd. (2015) \\
\hline & C. resinosa & + & + & + & T.E & Downes vd. (2015) \\
\hline & C. setosa & + & + & - & T.E & Downes vd. (2015) \\
\hline & C. teretifolia & + & + & - & T.E & Downes vd. (2015) \\
\hline \multirow{6}{*}{ Lamiaceae } & Ballota acetabulosa & + & + & - & + & $\mathrm{Bu}$ çalışma \\
\hline & Phlomis lycia & + & - & - & + & $\mathrm{Bu}$ çalışma \\
\hline & Stachys cretica & - & + & - & + & Çatav vd. (2018) \\
\hline & S. cretica & + & + & - & + & $\mathrm{Bu}$ çalışma \\
\hline & Teucrium chamaedrys & - & - & - & + & $\mathrm{Bu}$ çalışma \\
\hline & Thymbra spicata & - & - & - & + & Çatav vd. (2018) \\
\hline Malvaceae & Alcea pallida & + & - & + & + & Çatav vd. (2018) \\
\hline Plantaginaceae & Chaenorhinum rubrifolium & + & + & + & + & Tavşanoğlu vd. (2017) \\
\hline \multirow{3}{*}{ Poaceae } & Avena barbata & - & - & - & + & Çatav vd. (2018) \\
\hline & Heteropogon contortus & + & - & + & T.E & Baldos vd. (2015) \\
\hline & Phleum exaratum & + & + & + & + & Çatav vd. (2018) \\
\hline Polygonaceae & Rumex tuberosus & + & + & + & + & Çatav vd. (2018) \\
\hline Proteaceae & Grevillea leucopteris & + & + & - & T.E & Downes vd. (2013) \\
\hline Restionaceae & Rhodocoma arida & + & - & + & T.E & Flematti vd. (2011) \\
\hline Rosaceae & Sanguisorba minor & - & - & - & + & Çatav vd. (2018) \\
\hline \multirow{2}{*}{ Stylidiaceae } & Stylidium affine & + & + & - & T.E & Flematti vd. (2011) \\
\hline & S. affine & + & + & - & T.E & Downes vd. (2013) \\
\hline
\end{tabular}




\section{Sonuçlar}

Çalışmamızın bulguları, Lamiaceae türlerinin dumana olan pozitif çimlenme tepkilerinde, $\mathrm{KAR}_{1}$ bileşiğinin önemli bir rol oynadığını göstermektedir. Siyanohidrin ise tek başına etkili olmamakla beraber, $\mathrm{KAR}_{1}$ ile birlikte uygulandığında çimlenme yüzdesini arttırabilmekte ya da sinerjistik bir etki yaratabilmektedir. Bu araştırmanın çıktıları, tıbbi ve ekonomik değere sahip Lamiaceae türlerinin çimlenme potansiyellerini arttırmak için kullanılabilir.

\section{Teşekkür}

Çalışmanın ilk yazarı, bu araştırmaya olan mali desteğinden dolayı Muğla Sitkı Koçman Üniversitesi Öğretim Üyesi Yetiştirme Programı (ÖYP) Koordinatörlüğü'ne teşekkür eder.

\section{Yazar Katkıları}

Şükrü Serter Çatav: Çalışmayı planlamış ve deneyleri gerçekleştirmiş, istatistiksel analizleri yapmış ve makaleyi yazmıştır.

Kenan Akbaş: Çalışmayı planlamış ve deneyleri gerçekleştirmiş, bitki teşhislerini yapmıştır.

\section{Çıkar Çatışması}

Yazarlar çıkar çatışması bildirmemişlerdir.

\section{Kaynaklar}

Arcamone, J. R. ve Jaureguiberry, P. (2018). Germination response of common annual and perennial forbs to heat shock and smoke treatments in the Chaco Serrano, central Argentina. Austral Ecology, 43(5), 567577. https://doi.org/10.1111/aec.12593

Baldos, O. C., DeFrank, J. ve Sakamoto, G. S. (2015). Germination response of dormant tanglehead (Heteropogon contortus) seeds to smoke-infused water and the smoke-associated stimulatory compounds, karrikinolide and cyanide. HortScience, 50(3), 421-429. https://doi.org/10.21273/HORTSCI.50.3.421

Burger, B. V., Pošta, M., Light, M. E., Kulkarni, M. G., Viviers, M. Z. ve van Staden, J. (2018). More butenolides from plant-derived smoke with germination inhibitory activity against karrikinolide. South African Journal of Botany, 115, 256-263. https://doi.org/10.1016/j.sajb.2018.01.023

Chuvieco, E., Giglio, L. ve Justice, C. (2008). Global characterization of fire activity: Toward defining fire regimes from Earth observation data. Global Change Biology, 14(7), 1488-1502. https://doi.org/10.1111/j.1365-2486.2008.01585.x

Çatav, Ş. S., Küçükakyüz, K., Akbaş, K. ve Tavşanoğlu, Ç. (2014). Smoke-enhanced seed germination in Mediterranean Lamiaceae. Seed Science Research, 24(3), 257-264. https://doi.org/10.1017/S0960258514000142

Çatav, Ş. S., Küçükakyüz, K., Tavşanoğlu, Ç. ve Akbaş, K. (2015). Effects of aqueous smoke and nitrate treatments on germination of 12 eastern Mediterranean Basin plants. Annales Botanici Fennici, 52, 93 100. https://doi.org/10.5735/085.052.0211

Çatav, Ş. S., Küçükakyüz, K., Tavşanoğlu, Ç. ve Pausas, J. G. (2018). Effect of fire-derived chemicals on germination and seedling growth in Mediterranean plant species. Basic and Applied Ecology, 30, 6575. https://doi.org/10.1016/j.baae.2018.05.005

Downes, K. S., Light, M. E., Pošta, M., Kohout, L. ve van Staden, J. (2013). Comparison of germination responses of Anigozanthos flavidus (Haemodoraceae), Gyrostemon racemiger and Gyrostemon ramulosus (Gyrostemonaceae) to smoke-water and the smoke-derived compounds karrikinolide $\left(\mathrm{KAR}_{1}\right)$ and glyceronitrile. Annals of Botany, 111(3), 489-497. https://doi.org/10.1093/aob/mcs300

Downes, K. S., Light, M. E., Pošta, M., Kohout, L. ve van Staden, J. (2014). Do fire-related cues, including smoke-water, karrikinolide, glyceronitrile and nitrate, stimulate the germination of 17 Anigozanthos taxa and Blancoa canescens (Haemodoraceae)? Australian Journal of Botany, 62, 347-358.

https://doi.org/10.1071/BT13189 
Downes, K. S., Light, M. E., Pošta, M. ve van Staden, J. (2015). Fire-related cues and the germination of eight Conostylis (Haemodoraceae) taxa, when freshly collected, after burial and after laboratory storage. Seed Science Research, 25(3), 286-298. https://doi.org/10.1017/S0960258515000227

Erik, S. ve Tarıkahya, B. (2004). Türkiye florası üzerine. Kebikeç, 17, 139-163.

Flematti, G. R., Ghisalberti, E. L., Dixon, K. W. ve Trengove, R. D. (2004). A compound from smoke that promotes seed germination. Science, 305, 977. https://doi.org/10.1126/science.1099944

Flematti, G. R., Merritt, D. J., Piggott, M. J., Trengove, R. D., Smith, S. M., Dixon, K. W. ve Ghisalberti, E. L. (2011). Burning vegetation produces cyanohydrins that liberate cyanide and stimulate seed germination. Nature Communications, 2, 360. https://doi.org/10.1038/ncomms1356

Gupta, S., Hrdlička, J., Ngoroyemoto, N., Nemahunguni, N. K., Guckỳ, T., Novák, O., Kulkarni, M. G., Doležal, K. ve Van Staden, J. (2020). Preparation and standardisation of smoke-water for seed germination and plant growth stimulation. Journal of Plant Growth Regulation, 39, 338-345. https://doi.org/10.1007/s00344-019-09985-y

He, T., Lamont, B. B. ve Pausas, J. G. (2019). Fire as a key driver of Earth's biodiversity. Biological Reviews, 94, 1983-2010. https://doi.org/10.1111/brv.12544

Kazancı, D. D. ve Tavşanoğlu, Ç. (2019). Heat shock-stimulated germination in Mediterranean Basin plants in relation to growth form, dormancy type and distributional range. Folia Geobotanica, 54(1), 85-98. https://doi.org/10.1007/s12224-019-09349-0

Keeley, J. E., Pausas, J. G., Rundel, P. W., Bond, W. J. ve Bradstock, R. A. (2011). Fire as an evolutionary pressure shaping plant traits. Trends in Plant Science, 16, 406-411. https://doi.org/10.1016/j.tplants.2011.04.002

Küçükakyüz, K. ve Çatav, Ş. S. (2021). Physiological effects of smoke-water and karrikinolide on wheat seedlings grown under boron stress. Russian Journal of Plant Physiology, 68(3), 552-558. https://doi.org/10.1134/S1021443721030092

Ma, H., Erickson, T. E., Walck, J. L. ve Merritt, D. J. (2020). Interpopulation variation in germination response to fire-related cues and after-ripening in seeds of the evergreen perennial Anigozanthos flavidus (Haemodoraceae). International Journal of Wildland Fire, 29(10), 950-960. https://doi.org/10.1071/WF19195

Moreira, B., Tormo, J., Estrelles, E. ve Pausas, J. G. (2010). Disentangling the role of heat and smoke as germination cues in Mediterranean Basin flora. Annals of Botany, 105, 627-635. https://doi.org/10.1093/aob/mcq017

Nelson, D. C., Flematti, G. R., Ghisalberti, E. L., Dixon, K. W. ve Smith, S. M. (2012). Regulation of seed germination and seedling growth by chemical signals from burning vegetation. Annual Review of Plant Biology, 63, 107-130. https://doi.org/10.1146/annurev-arplant-042811-105545

Newton, R. J., Bond, W. J. ve Farrant, J. M. (2006). Effects of seed storage and fire on germination in the nutfruited Restionaceae species, Cannomois virgata. South African Journal of Botany, 72, 177-180. https://doi.org/10.1016/j.sajb.2005.05.005

Quílez, M., Ferreres, F., López-Miranda, S., Salazar, E. ve Jordán, M. J. (2020). Seed oil from Mediterranean aromatic and medicinal plants of the lamiaceae family as a source of bioactive components with nutritional. Antioxidants, 9(6), 510. https://doi.org/10.3390/antiox9060510

Simpson, M. G. (2010). Plant systematics. Amsterdam: Elsevier.

Tavşanoğlu, Ç., Ergan, G., Çatav, Ş. S., Zare, G., Küçükakyüz, K. ve Özüdoğru, B. (2017). Multiple firerelated cues stimulate germination in Chaenorhinum rubrifolium (Plantaginaceae), a rare annual in the Mediterranean Basin. Seed Science Research, 27(1), 26-38.

https://doi.org/10.1017/S0960258516000283 